\title{
BADANIE WŁAŚCIWOŚCI LOTNICZEGO SYSTEMU PRZECIWPOŻAROWEGO SSP-FK W ASPEKCIE FAŁSZYWEGO ZADZIAŁANIA
}

\begin{abstract}
W artykule przedstawiono wybrane wyniki prac realizowanych w Instytucie Technicznym Wojsk Lotniczych w zakresie badań systemu przeciwpożarowego SSP-FK (jako jednego z głównych systemów pokładowych) stosowanego na wielu typach wojskowych statków powietrznych eksploatowanych w Siłach Zbrojnych RP. Dla określania warunków fałszywego sygnalizowania pożaru opracowano modele symulacyjne działania bloków wykonawczych systemu SSP-FK. Badania modeli symulacyjnych wykonano w pakietach obliczeniowych Matlab-Simulink i Circuit-Maker. Wyniki tych prac zostały wykorzystane do diagnostyki wybranych modułów systemu SSP-FK w trakcie badania rzeczywistych przypadków fałszywego zadziałania tych urządzeń.
\end{abstract}

Słowa kluczowe: lotnicze instalacje gaśnicze, metody badań i zabezpieczeń

\section{Wprowadzenie}

Jednym z podstawowych systemów pokładowych zarówno cywilnych jak i wojskowych statków powietrznych jest system przeciwpożarowy, występujący w postaci prostej instalacji gaśniczej (uruchamianej przez pilota) lub złożonego układu automatycznego wykrywania i gaszenia pożaru [5].

Jednym z takich systemów jest system SSP-FK, eksploatowany na wielu typach wojskowych statków powietrznych m.in. na śmigłowcach z rodziny W-3/3W/3WA/3PL i Mi-8/14/17/24 oraz samolotach An-28 i Tu-154M. Niesprawności systemu przeciwpożarowego SSP-FK, w szczególności przypadki jego fałszywego zadziałania (włącznie z uruchomieniem zaworów i butli gaśniczych) wskazują, że wymaga on dodatkowych badań diagnostycznych $[5,7,8]$. Wykonane w Instytucie Technicznym Wojsk Lotniczych analizy statystyczne przypadków fałszywego (samoczynnego) zadziałania lotniczego systemu przeciwpożarowego SSP-FK wykazały, że wśród przyczyn wywołujących takie za-

\footnotetext{
1 Autor do korespondencji/corresponding author: Krzysztof Głyda, Instytut Techniczny Wojsk Lotniczych, 01-494 Warszawa, ul. Księcia Bolesława 6, 261-851-133, krzysztof.glyda@itwl.pl

2 Andrzej Szelmanowski, Instytut Techniczny Wojsk Lotniczych, 01-494 Warszawa, ul. Księcia Bolesława 6, 261-851-603, andrzej.szelmanowski@itwl.pl
} 
chowanie jako główne wymieniane są niesprawności bloku wykonawczego, obwodów elektrycznych i nadajników pożaru [4]. Brak jest jednak bezpośredniego powiązania pomiędzy objawami w postaci fałszywego zadziałania systemu przeciwpożarowego, a zidentyfikowanymi niesprawnościami elementów składowych tego systemu. Fakt ten może wskazywać na zakłócenia w sieci elektroenergetycznej jako prawdopodobne przyczyny wywołania stanów dynamicznych bloku wykonawczego, powodujących obserwowane efekty [3, 6].

Należy zaznaczyć, że rozwiązanie problemów z fałszywą sygnalizacją pożaru systemu SSP-FK jest zagadnieniem ważnym dla bezpiecznej eksploatacji samolotów i śmigłowców wojskowych, gdyż jest on jednocześnie systemem prewencyjnym (ostrzegającym załogę o możliwości wystąpienia pożaru) oraz ratowniczym (mającym ugasić pożar w każdej fazie wykonywanego lotu).

Dla przykładu, w skład systemu przeciwpożarowego SSP-FK zabudowanego na śmigłowcu Mi-8 (rys. 1.) wchodzi 12 grup nadajników DPS umieszczonych w 4 kontrolowanych przedziałach (m.in. pieca grzewczego KO-50) oraz 2 elektroniczne bloki wykonawcze SSP-FK-BI. Głównym elementem sterującym pracą systemu przeciwpożarowego jest blok wykonawczy SSP-FK-BI, zawierający 6 płytek elektronicznych zwanych płytkami wzmacniaczy [1].
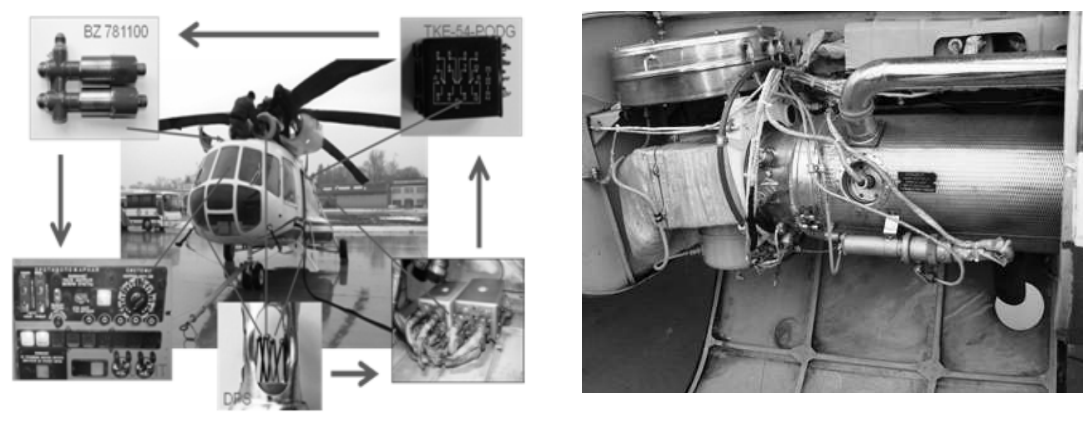

Rys. 1. Widok elementów systemu SSP-FK (po lewej) oraz pieca grzewczego KO-50 (po prawej)

Fig. 1. View of components of SSP-FK system (left) and heating device KO-50 (right)

Na podstawie analizy działania systemu przeciwpożarowego SSP-FK oraz badań wykonanych na pokładzie śmigłowca Mi-8 jako możliwą przyczynę jego fałszywego zadziałania przyjęto zjawisko generacji sygnału pożaru w obwodzie wyjściowym płytki wzmacniaczy (wchodzącej w skład bloku wykonawczego SSP-FK-BI) na skutek oddziaływania impulsów zakłócających w jej obwodach zasilania, przy jednoczesnym występowaniu napięcia podprogowego z nadajników DPS, generowanego podczas zmian temperatury powietrza otoczenia [9]. 


\section{Komputerowe modelowanie właściwości i badanie warunków fałszywego zadziałania systemu przeciwpożarowego SSP-FK}

Liczne przypadki nieprawidłowej pracy systemu przeciwpożarowego SSP-FK (m.in. zdarzenie analizowane w ramach Komisji Badania Wypadków Lotniczych powołanej dla ustalenia przyczyn uruchomienia butli gaśniczej samolotu An-28), wymusiły opracowanie komputerowych metod analizy właściwości i badania warunków fałszywego zadziałania jego wybranych elementów.

W Instytucie Technicznym Wojsk Lotniczych opracowano modele numeryczne obwodów elektrycznych płytek wzmacniaczy bloków wykonawczych SSP-FK-BI i BI-2A, przy wykorzystaniu pakietu obliczeniowego CircuitMaker. Badania rozpoczęto od modelowania właściwości torów sygnałowych bloku wykonawczego, a następnie wykonano określenie warunków jego samoczynnego zadziałania m.in. podczas występowania zakłóceń w zasilaniu $[6,8]$.

Wykonano także badania modeli numerycznych nadajników pożaru, przy wykorzystaniu pakietu Matlab-Simulink. Badania te miały na celu sprawdzenie możliwości generacji w nadajnikach DPS napięcia uruchamiającego system SSP-FK na skutek zmian temperatury otoczenia (oddziaływanie mrozu, podmuch zimnego lub gorącego powietrza). Umożliwiły one określenie wartości sygnału wyjściowego dla założonych warunków termicznych.

Do badania właściwości torów sygnałowych systemu SSP-FK opracowano modele numeryczne dwóch typów nadajników (rys. 2.): DPS (z pojedynczym układem spoin) stosowanych dla bloków SSP-FK-BI i bardziej czułych DTBG (z podwójnym układem spoin) stosowanych dla bloków BI-2A.
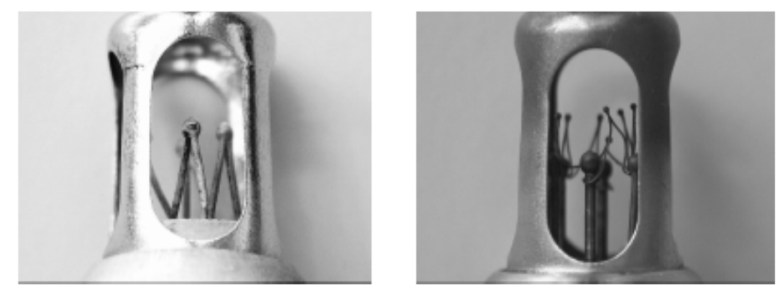

Rys. 2. Widok spoin termoelektrycznych nadajników DPS (po lewej) oraz DTBG (po prawej)

Fig. 2. View of joints of thermoelectric transmitters DPS (left) and DTBG (right)

Modele numeryczne funkcjonowania nadajników DPS i DTBG opracowano z wykorzystaniem pakietu obliczeniowego Matlab-Simulink [8]. Do badania właściwości torów sygnałowych wykorzystano standardowe generatory sygnałów (rys. 3.), charakteryzujące wybrane warunki termiczne występującego w strefach dozorowanych przez nadajniki pożaru [9]. Dla określonych w procesie identyfikacji parametrów nadajników pożaru testowano różne postacie wymuszeń termicznych (m.in. narastające liniowo i skokowe zmiany temperatury). 


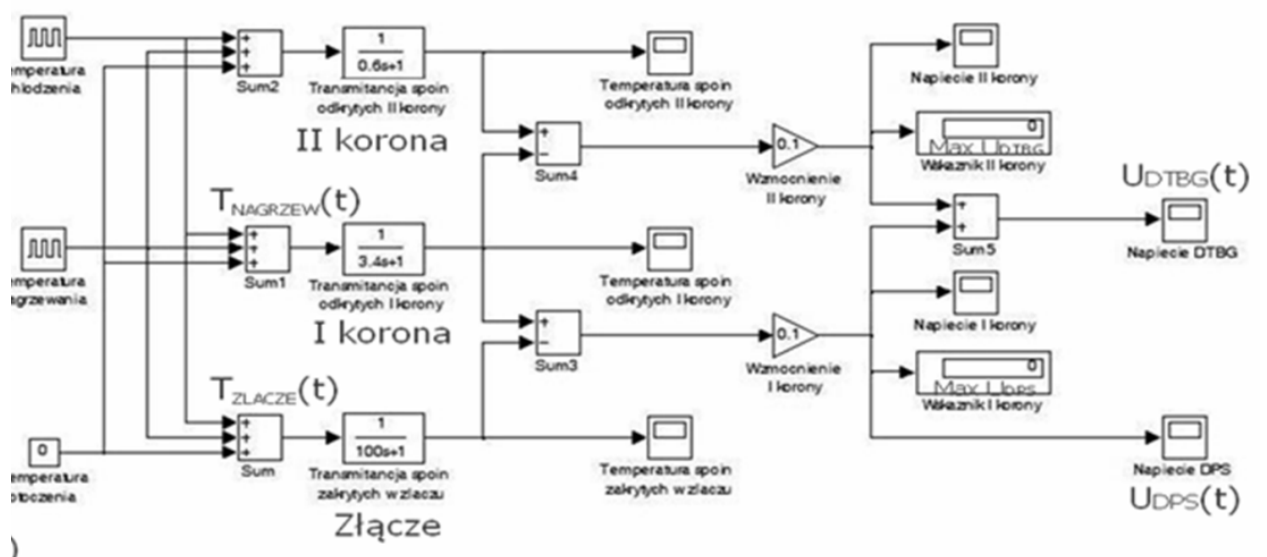

Rys. 3. Model symulacyjny wykorzystywany do badania nadajników pożaru DPS i DTBG

Fig. 3. Simulation model used to study fire transmitters DPS and DTBG

Do badania właściwości torów przetwarzania sygnałów systemu SSP-FK opracowano modele numeryczne płytki wzmacniaczy dla bloku wykonawczego SSP-FK-BI oraz BI-2A (rys. 4.). Z uwagi na podobieństwo funkcji i parametrów elementów elektronicznych płytki wzmacniaczy bloku SSP-FK-BI i bloku BI-2A, w opracowanych modelach wykorzystano te same symbole i schematy połączeń dla elementów i ścieżek obwodów elektrycznych [5].
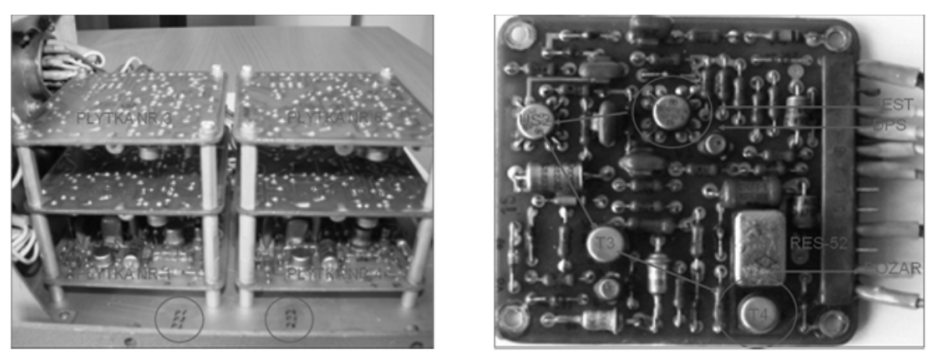

Rys. 4. Widok wnętrza bloku wykonawczego (po lewej) oraz płytki wzmacniaczy (po prawej)

Fig. 4. View of the interior of the executing block (left) and modules of amplifiers (right)

W opracowanym modelu (rys. 5.) wykorzystano standardowe moduły pakietu Circuit-Maker oraz ustawiono parametry charakteryzujące elementy elektroniczne występujące na płytce wzmacniaczy bloków wykonawczych [5, 8]. Pozwoliło to na badanie wpływu spadku napięcia zasilania na wartości sygnału z nadajników pożaru, wymagane do zadziałania systemu SSP-FK w symulowanych warunkach skokowego wzrostu temperatury (np. podczas włączenia wentylatora pieca grzewczego KO-50). 


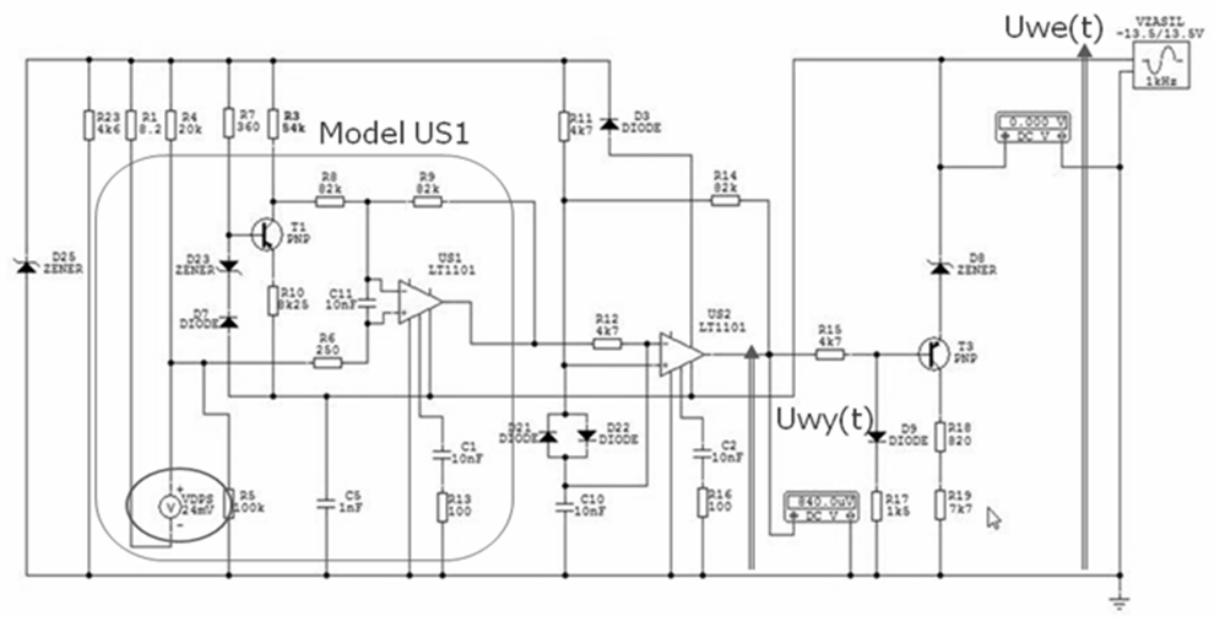

Rys. 5. Model symulacyjny wykorzystywany do badania bloku wykonawczego SSP-FK-BI

Fig. 5. Simulation model used to study the SSP-FK-BI executing block

Na podstawie badań symulacyjnych modeli torów sygnałowych (w nadajnikach pożaru) i torów przetwarzania (w bloku wykonawczym) stwierdzono, że pojawienie się spadku napięcia zasilania (np. przy włączeniu rozrusznika GS-18 lub wentylatora pieca grzewczego KO-50 na śmigłowcu Mi-8) podczas występowania napięcia w obwodzie nadajników pożaru DPS lub DTBG o wartości podprogowej (spowodowanego zmianą temperatury powietrza w przedziale pieca KO-50) może być przyczyną fałszywego zadziałania systemu SSP-FK.

Stwierdzono również, że dla warunków normalnej pracy pieca grzewczego KO-50 skokowe ochłodzenie nadajników pożaru (np. od podmuchu zimnego wiatru) nie powoduje wzrostu generowanej w nich siły termoelektrycznej do wartości progowej i bez wystąpienia zakłóceń w zasilaniu bloku wykonawczego nie może być przyczyną samoczynnego zadziałania systemu SSP-FK [8].

\section{Weryfikacja właściwości torów sygnałowych i warunków fałszywego zadziałania systemu przeciwpożarowego SSP-FK}

W celu weryfikacji wyników otrzymanych $\mathrm{w}$ badaniach symulacyjnych opracowanych modeli numerycznych bloku wykonawczego SSP-FK-BI, wykonano pomiary wartości napięć uruchomienia i podtrzymania uruchomienia zadziałania badanego bloku wykonawczego dla wybranych wartości sygnału otrzymywanego z grupy nadajników pożaru DPS, przy jednoczesnym wytwarzaniu spadku napięcia zasilania bloku wykonawczego [2, 6, 9].

Badania przeprowadzono dla bloku „suchego” oraz „mokrego”, poddanego oddziaływaniu wilgoci (rys. 6.). Stwierdzono, że pod wpływem wilgoci zmianie mogą ulec wartości parametrów torów pomiarowych tworzonych przez elemen- 
ty elektroniczne występujące na płytce wzmacniaczy bloku wykonawczego (m.in. wartości parametrów kondensatorów, tranzystorów i układów scalonych).
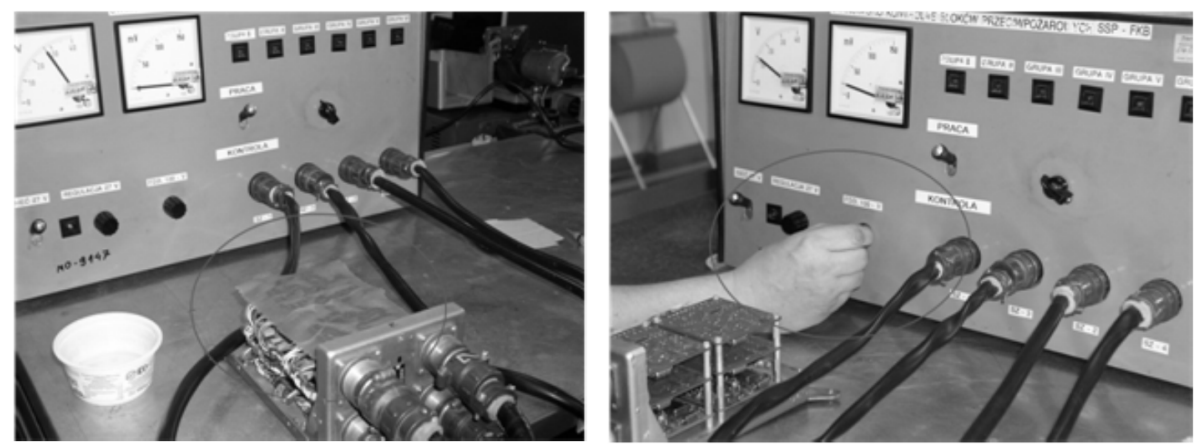

Rys. 6. Widok urządzenia do wprowadzania wilgoci (po lewej) oraz określania progów zadziałania (po prawej)

Fig. 6. View of the device oriented for introduction of moisture (left) and determining the levels of activation (right)

Określenie właściwości dynamicznych bloku wykonawczego SSP-FK-BI w zakresie jego zadziałania podczas jednoczesnego wystąpienia spadku napięcia zasilania i sygnału z nadajników pożaru o wartości podprogowej (nie wywołującej zadziałania bloku przy znamionowym napięciu zasilania) było możliwe na stanowisku badawczym (rys. 6.) wykorzystywanym w Wojskowych Zakładach Lotniczych WZL-1 S.A. w Łodzi. Precyzyjne ustalenie parametrów takiego zachowania bloku wykonawczego wymagało zbudowania w Instytucie Technicznym Wojsk Lotniczych specjalizowanego generatora sygnałów o amplitudzie rzędu miliwoltów oraz czasie trwania rzędu milisekund [6, 9].

Przykładowe wartości napięcia dla sygnału uruchamiającego z nadajnika pożaru DPS przy spadku napięcia zasilania [8] dla bloku wykonawczego SSP-FK-BI w stanie suchym (bez oddziaływania wilgoci) podano w tabeli 1. Otrzymane wyniki wykazały, że istnienie obszaru napięcia uruchomienia, występuje już dla sygnałów z nadajników pożaru o wartości $23 \mathrm{mV}$. Wymagane napięcie zasilania bloku wykonawczego, mogące spowodować jego fałszywe zadziałanie, powinno osiągać wartości na poziomie $12 \mathrm{~V}$ [8]. Występowanie obszaru zadziałania związane jest $\mathrm{z}$ właściwościami torów pomiarowych bloku wykonawczego SSP-FK-BI i powoduje, że podczas spadku napięcia zasilania sygnał z nadajników pożaru jest wyższy niż napięcie odniesienia na komparatorze wzmacniacza operacyjnego wybranej płytki.

Przykładowe wartości napięcia dla sygnału uruchamiającego z nadajnika pożaru przy spadku napięcia zasilania [8] dla bloku wykonawczego SSP-FK-BI $\mathrm{w}$ stanie mokrym (po przetrzymaniu w warunkach wilgoci) podano w tabeli 2 . Otrzymane wyniki wykazały nieznaczne obniżenie wartości sygnału z nadajników pożaru wymaganej do uruchomienia bloku wykonawczego. 
Na podstawie otrzymanych wyników pomiarów w zakresie wartości sygnału z nadajnika pożaru wymaganego do uruchomienia bloku wykonawczego SSP-FK-BI przy spadku napięcia w jego obwodzie zasilania, zbudowano zbiorczy wykres (rys. 7.), przedstawiający obszar uruchomienia bloku oraz obszar podtrzymania jego uruchomienia [8].

Tabela 1. Wartości napięcia z nadajnika pożaru powodującego zadziałanie bloku wykonawczego w stanie suchym

Table 1. Values of the voltage of the fire transmitter causing tripping action of executing block in a dry state

\begin{tabular}{|c|c|c|c|c|}
\hline $\begin{array}{c}\text { Napięcie } \\
\text { zasilania } \\
\text { bloku }\end{array}$ & $\begin{array}{c}\text { Napięcie zadziałania i odpuszczenia } \\
\text { bloku wykonawczego } \\
\text { płytka najbardziej czuła }\end{array}$ & \multicolumn{2}{|c|}{$\begin{array}{c}\text { Napięcie zadziałania i odpuszczenia } \\
\text { bloku wykonawczego } \\
\text { płytka najmniej czuła }\end{array}$} \\
\hline$[\mathrm{V}]$ & {$[\mathrm{mV}]$} & {$[\mathrm{mV}]$} & {$[\mathrm{mV}]$} & {$[\mathrm{mV}]$} \\
\hline 12 & 23,5 & 21,6 & 25,5 & 23,7 \\
\hline 16 & 28,1 & 25,0 & 29,6 & 26,6 \\
\hline 20 & 29,8 & 26,8 & 30,4 & 27,7 \\
\hline 24 & 30,0 & 26,9 & 30,5 & 27,8 \\
\hline 28 & 30,0 & 27,0 & 30,7 & 27,9 \\
\hline 32 & 30,2 & 27,1 & 30,8 & 28,1 \\
\hline
\end{tabular}

Tabela 2. Wartości napięcia z nadajnika pożaru powodującego zadziałanie bloku wykonawczego w stanie mokrym

Table 2. Values of the voltage of the fire transmitter causing tripping action of executing block in a wet state

\begin{tabular}{|c|c|c|c|c|}
\hline $\begin{array}{c}\text { Napięcie } \\
\text { zasilania } \\
\text { bloku }\end{array}$ & \multicolumn{2}{|c|}{$\begin{array}{c}\text { Napięcie zadziałania i odpuszczenia } \\
\text { bloku wykonawczego } \\
\text { płytka najbardziej czuła }\end{array}$} & \multicolumn{2}{|c|}{$\begin{array}{c}\text { Napięcie zadziałania i odpuszczenia } \\
\text { bloku wykonawczego } \\
\text { płytka najmniej czuła }\end{array}$} \\
\hline$[\mathrm{V}]$ & {$[\mathrm{mV}]$} & {$[\mathrm{mV}]$} & {$[\mathrm{mV}]$} & {$[\mathrm{mV}]$} \\
\hline 12 & 22,8 & 22,0 & 25,1 & 24,3 \\
\hline 16 & 27,8 & 25,2 & 29,2 & 26,9 \\
\hline 20 & 29,4 & 27,0 & 30,3 & 27,9 \\
\hline 24 & 29,6 & 27,2 & 30,4 & 28,2 \\
\hline 28 & 29,7 & 27,2 & 30,5 & 28,3 \\
\hline 32 & 29,8 & 27,3 & 30,6 & 28,4 \\
\hline
\end{tabular}

Wykres ten pokazuje, że uruchomienie bloku wykonawczego może nastąpić dla sygnałów z nadajników pożaru mniejszych niż wartości podawane przez producenta dla znamionowego napięcia zasilania $(28 \div 32 \mathrm{mV})$. Pozwala też zrozumieć, dlaczego nie każdy spadek napięcia w zasilaniu elektrycznym wywołuje zadziałanie bloku. Dla wywołania fałszywego zadziałania bloku spadek napięcia musi posiadać wartości mieszczące się w obszarze zadziałania, a po przejściu w obszar podtrzymania zadziałania musi on trwać wystarczająco długo, aż na- 
stąpi przełączenie układów samopodtrzymania zasilania bloku. Obszar podtrzymania zadziałania umożliwia uruchomienie bloku dla czasów spadku napięcia zasilania krótszych niż wymagane w obszarze zadziałania [8].

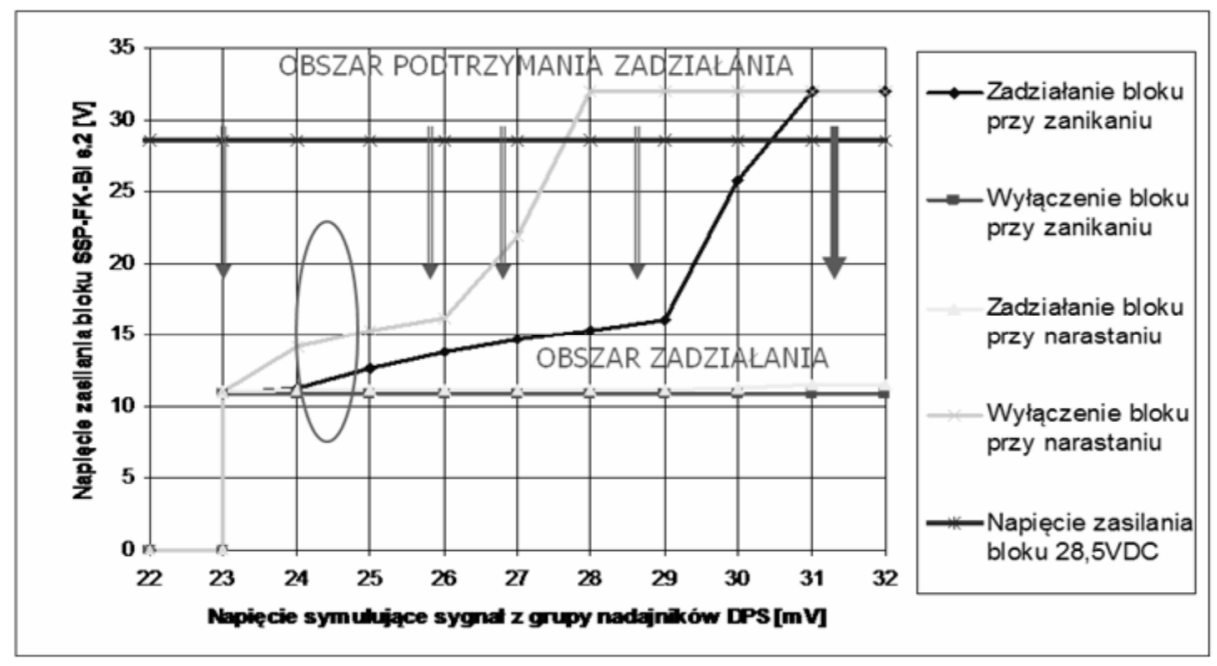

Rys. 7. Wykres obrazujący warunki fałszywego zadziałania bloku wykonawczego SSP-FK-BI

Fig. 7. Diagram showing the conditions of false activating of the SSP-FK-BI executing block

Otrzymane wyniki wykazały, że istnienie obszaru podtrzymania zadziałania bloku wykonawczego występuje jako rozszerzenie obszaru uruchomienia zadziałania i rozpoczyna się dla sygnałów z nadajników pożaru o wartości $23 \mathrm{mV}$.

Parametrem determinującym wystąpienie fałszywego zadziałania bloku wykonawczego jest też czas trwania spadku napięcia zasilania. Badania wykazały, że im mniejsze jest napięcie zasilania podczas spadku, tym wymagany jest dłuższy czas trwania spadku napięcia zasilania [8].

\section{Podsumowanie}

Przeprowadzone badania wykazały, że lotniczy system przeciwpożarowy SSP-FK, z uwagi na wykorzystywane w nim bloki wykonawcze zawierające wzmacniacze operacyjne, stanowi złożony obiekt dynamiczny charakteryzujący się specyficznymi właściwościami w swoim funkcjonowaniu w zależności od rodzaju zakłóceń w jego zasilaniu. Jednymi z zakłóceń, wywołującymi jego fałszywe zadziałanie są spadki napięcia zasilania, spowodowane włączaniem do sieci elektroenergetycznej odbiorników dużej mocy.

Przeprowadzone badania symulacyjne, potwierdzone badaniami weryfikacyjnymi na śmigłowcu Mi-8, wykazały, że fałszywe zadziałanie systemu prze- 
ciwpożarowego SSP-FK może być wywołane włączeniem/wyłączeniem takich instalacji jak: obwodu zasilania rozrusznika GS-18, przeciwoblodzeniowych elementów grzewczych oraz wentylatora pieca grzewczego KO-50.

Dodatkowo stwierdzono, że bloki wykonawcze SSP-FK-BI posiadają progi sygnałowe wymagane dla ich zadziałania w zależności od stopnia zawilgocenia. Progi te tworzą obszar uruchomienia bloku wykonawczego SSP-FK-BI oraz obszar podtrzymania jego uruchomienia, i są odpowiedzialne za fałszywe zadziałanie bloku podczas jednoczesnego występowania spadków napięcia zasilania w sieci elektroenergetycznej i sygnału z nadajników pożaru.

Otrzymane wyniki badań umożliwiły również sprecyzowanie wymagań na wprowadzenie dodatkowych układów stabilizacji napięcia zasilania systemu przeciwpożarowego SSP-FK, zalecanych jako jeden z możliwych sposobów zabezpieczenia przed wystąpieniem jego fałszywego zadziałania na skutek zakłóceń występujących w zasilaniu elektroenergetycznym sieci pokładowej.

Zalecana kontynuacja podjętych przez ITWL prac w zakresie próby uogólnienia otrzymanych wyników badań systemu przeciwpożarowego dla analizy jego otoczenia (m.in. doboru parametrów systemu odpowiednio do wymagań eksploatowanych lub projektowanych statków powietrznych, różnych dla śmigłowców i samolotów) wymaga zapewnienia odpowiednich sił i środków i może być dalej realizowana np. w ramach prac lub na zlecenie Komisji Badania Wypadków Lotniczych LP lub Inspektoratu Wsparcia Sił Zbrojnych RP.

\section{Literatura}

[1] Dowództwo Wojsk Lotniczych: Śmigłowiec Mi-8, Eksploatacja i obsługa osprzętu, Wyd. MON, Poznań 1970.

[2] Lewitowicz J.: Podstawy eksploatacji statków powietrznych, Badania eksploatacyjne statków powietrznych, Tom 4, Wyd. ITWL, Warszawa 2007.

[3] Lindstedt P.: Praktyczna diagnostyka maszyn i jej teoretyczne podstawy, Wydawnictwo Naukowe AKSON, Warszawa 2002.

[4] Materiały analityczne Instytutu Technicznego Wojsk Lotniczych: Zestawienie przypadków fałszywego zadziałania instalacji przeciwpożarowej SSP-FK w latach 2010-2014, System Informatyczny SI SAMANTA, Warszawa 2015.

[5] Michalak S., Szelmanowski A., Skoczylas D., Gierat J.: Badanie przyczyn fałszywego zadziaływania instalacji przeciwpożarowych. Protokół z badań, Biblioteka Techniczna Instytutu Technicznego Wojsk Lotniczych, Warszawa 1993.

[6] Norma Obronna Ministerstwa Obrony Narodowej: Wojskowe statki powietrzne, Pokładowe układy zasilania elektrycznego, Podstawowe parametry, wymagania i badania, NO-15-A200:2007.

[7] Szelmanowski A., Borowski J., Sajda K., Gajewski T., Sekuła A.: Badania przyczyn nieprawidłowego działania bloków wzmacniaczy instalacji przeciwpożarowej SSPFK-BI, Protokół z badań, Biblioteka Techniczna Instytutu Technicznego Wojsk Lotniczych, Warszawa 2010. 
[8] Szelmanowski A., Głyda K., Tokarski T., Gajewski T., Kalisiak M., Sekuła A.: Badania możliwości samoczynnego zadziałania instalacji przeciwpożarowej SSP-FK śmigłowca Mi-8 przy zaniku / spadku napięcia zasilania, Protokół z badań, Biblioteka Techniczna Instytutu Technicznego Wojsk Lotniczych, Warszawa 2015.

[9] Szelmanowski A., Głyda K., Gajewski T.: Badania wybranych urządzeń instalacji przeciwpożarowej SSP-FK śmigłowca Mi-8, Badania laboratoryjne elektryczne i termiczne, Program i metodyki badań, Biblioteka Techniczna Instytutu Technicznego Wojsk Lotniczych, Warszawa 2015.

\section{STUDY OF PROPERTIES OF THE SSP-FK AIRCRAFT FIRE SUPPRESSION SYSTEM IN TERMS OF FALSE ACTIVATION}

\section{S u m m a r y}

The paper presents selected results of work in the Air Force Institute of Technology in research of fire suppression system SSP-FK (as one of main protection systems on-board) used on many types of military aircraft operated in the Polish Armed Forces. In determining the terms of the false signaling of fire, simulation models of action blocks implementing of SSP-FK suppression system have been developed. The study of simulation models have been made in MatlabSimulink and Circuit-Maker computing packages. The results of these works have been used to diagnose selected modules of SSP-FK system during the study of actual cases of false activation of these devices.

Keywords: aircraft fire suppression installations, methods of research and protection

DOI: $10.7862 / \mathrm{rm} .2017 .16$

Otrzymano/received: 11.10 .2016

Zaakceptowano/accepted: 2.03.2017 